\title{
Restoring the Public Trust in Physician-Scientists
}

\section{Richard M Fleming ${ }^{1 *}$, Matthew R Fleming ${ }^{1}$ and Tapan K Chaudhuri ${ }^{2}$}

${ }^{1}$ FHHI-OmnificImaging-Camelot, El Segundo, CA, USA

${ }^{2}$ Eastern Virginia Medical School, Norfolk, VA, USA

*Corresponding Author: Richard M Fleming, FHHI-OmnificImaging-Camelot, El Segundo, CA, USA.

Received: September 05, 2019; Published: September 12, 2019

DOI: $10.31080 /$ ASPS.2019.03.0396

Recently Jain., et al. [1] addressed one of the fundamental problems medical research has been facing for decades - the loss of physician-scientists, who are capable of translating basic research into clinical medicine.

It is clear that the general public trusts physician-scientists who are independently working on behalf of patients, without undue influence by Big Pharma or Big Food corporations [2-4]. Once that line is crossed, the trust can be lost [2-4]. It is critical that we restore the public trust and encourage young people to become physician-scientists.

To restore the public trust and to maintain our independence from corporate influences, it is important that we demonstrate a willingness to transparently discuss our data and prove its validity [5] and we must teach our young physician-scientists to do the same. Only by doing so, will we be able to openly and honestly discuss research and treatment options with our patients and restore their trust in us; trust which is the foundation of both the physician-scientist and the patient-physician relationship.

\section{Bibliography}

1. Jain MK., et al. "Saving the Endangered Physician-Scientist A Plan for Accelerating Medical Breakthroughs". NEJM 381 (2019): 399-402.

2. Funk C., et al. "Trust and Mistrust in Americans' Views of Scientific Experts". Pew Research Center (2019).

3. George SL and Buyse M. "Data fraud in clinical trials". Journal of Clinical Investigation 5 (2015): 161-173.

4. Keller F., et al. "The relationship between the physician and pharmaceutical industry: background ethics and regulatory proposals". Croatian Medical Journal 57 (2016): 398-401.

5. Fleming RM., et al. "Establishing Data Validity: Statistically Determining if Data is Fabricated, Falsified or Plagiarized". Acta Scientific Medical Sciences 3 (2019): 169-191.

\section{Volume 3 Issue 10 October 2019}

(C) All rights are reserved by Richard M Fleming., et al. 